San Jose State University

SJSU ScholarWorks

Master's Theses

Master's Theses and Graduate Research

1989

\title{
The Relationship between optokinetic nystagmus and hand dominance in children
}

Tina Thompson Virshup

San Jose State University

Follow this and additional works at: https://scholarworks.sjsu.edu/etd_theses

\section{Recommended Citation}

Virshup, Tina Thompson, "The Relationship between optokinetic nystagmus and hand dominance in children" (1989). Master's Theses. 3115.

DOI: https://doi.org/10.31979/etd.7g5w-a5a6

https://scholarworks.sjsu.edu/etd_theses/3115

This Thesis is brought to you for free and open access by the Master's Theses and Graduate Research at SJSU ScholarWorks. It has been accepted for inclusion in Master's Theses by an authorized administrator of SJSU ScholarWorks. For more information, please contact scholarworks@sjsu.edu. 


\section{INFORMATION TO USERS}

The most advanced technology has been used to photograph and reproduce this manuscript from the microfilm master. UMI films the text directly from the original or copy submitted. Thus, some thesis and dissertation copies are in typewriter face, while others may be from any type of computer printer.

The quality of this reproduction is dependent upon the quality of the copy submitted. Broken or indistinct print, colored or poor quality illustrations and photographs, print bleedthrough, substandard margins, and improper alignment can adversely affect reproduction.

In the unlikely event that the author did not send UMI a complete manuscript and there are missing pages, these will be noted. Also, if unauthorized copyright material had to be removed, a note will indicate the deletion.

Oversize materials (e.g., maps, drawings, charts) are reproduced by sectioning the original, beginning at the upper left-hand corner and continuing from left to right in equal sections with small overlaps. Each original is also photographed in one exposure and is included in reduced form at the back of the book. These are also available as one exposure on a standard $35 \mathrm{~mm}$ slide or as a $17^{\prime \prime} \times 23^{\prime \prime}$ black and white photographic print for an additional charge.

Photographs included in the original manuscript have been reproduced xerographically in this copy. Higher quality $6^{\prime \prime} \times 9^{\prime \prime}$ black and white photographic prints are available for any photographs or illustrations appearing in this copy for an additional charge. Contact UMI directly to order.

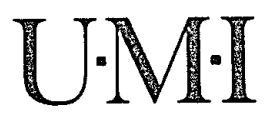


$-$ 
Order Number 1337849

The relationship between optokinetic nystagmus and hand dominance in children

Virshup, Tina Thompson, M.S.

San Jose State University, 1989

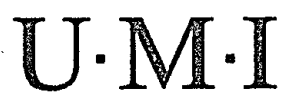

300 N. Zeeb Rd.

Ann Arbor, MI 48106 



\title{
THE RELATIONSHIP BETWEEN OPTOKINETIC NYSTAGMUS \\ AND HAND DOMINANCE IN CHILDREN
}

\author{
A Thesis \\ Presented to \\ The Faculty of the Department of Occupational Therapy \\ San Jose State University
}

\author{
In Partial Fulfillment \\ of the Requirements for the Degree \\ Master of Science
}

by

Tina Thompson Virshup

May, 1989 
APPROVED FOR THE DEPARTMENT OF OCCUPATIONAL THERAPY

soy X.mcoumank

Guy L.QAcCormack, M.S., OTR

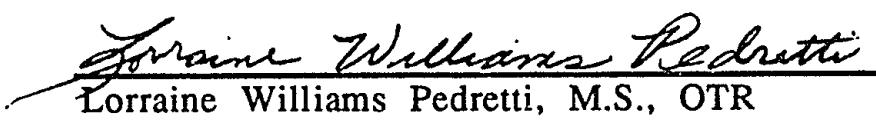

$\frac{\text { Janet Down, M.S., OTR }}{\text { Ja te }}$

APPROVED FOR THE UNIVERSITY

In. Lou Leurandousta. 


\begin{abstract}
The relationship between optokinetic nystagmus and hand dominance was investigated in 68 kindergarten children. The Knickerbocker timed hammering sample was used to determine hemispheric specialization and the optokinetic tape was used to determine absence or presence of optokinetic nystagmus. This study found a significant relationship between optokinetic nystagmus and hand dominance in a sample of developmentally delayed subjects. This relationship was not found in a sample of developmentally normal subjects. An unexpected and significant correlation was also found to exist between optokinetic nystagmus and rated developmental scores as measured by the Gesell Test for School Readiness.
\end{abstract}




\section{Acknowledgements}

Acknowledgement is gratefully given to: my faculty advisor Guy McCormack, M.S., OTR, who inspired and guided this research; committee members Lorraine Williams Pedretti, M.S., OTR, and Janet Down, M.S., OTR, for their assistance; Lela Llorens, Ph.D., OTR/L, FAOTA, for her valuable editorial assistance; Frank Wilkens and the kindergarten teachers at McCollam elementary school who allowed me into their classrooms to conduct research; the kindergarten students whose participation made this study a success; Catherine Greeno for her assistance with statistical analysis and interpretation; my parents, whose love and support made my educational dreams a reality; and last but not least special thanks to Gary Virshup who, with his love, encouragement, and Macintosh, kept me going throughout. 
Abstract

iii

Acknowledgements iv

List of Tables viii

Chapter 1 Introduction 1

Purpose _- 1

Statement of the Problem 2

Objective and Question __ 3

Definitions — 4

Assumptions — 5

Limitations

Significance of the Study 6

Chapter 2 Review of the Literature 9

Vestibular System _ 9

Hand Dominance $\longrightarrow 13$

Summary 14

Chapter 3 Design and Methodology 15

Objective and Question _ 15

Subjects 15

Collection Techniques —_ 15

Procedures 16

Serendipity $ـ \quad 17$ 
Table of Contents, Continued

Chapter $4 \quad$ Data and Results _ 19

Incorporation of Gesell School Readiness Data _ 19

Statistical Technique — 20

Demographic Data 20

Level of Development__ 22

Standard or Developmental Class _ 22

Gesell Score for School Readiness _ 24

Age and Development Scores _ 25

Age, Optokinetic Nystagmus, and Development 27

Age, Optokinetic Nystagmus, and Class 28

Age, Optokinetic Nystagmus, and Gesell Score —_ 28

The Relationship of Hand Dominance to Absence of Optokinetic

Nystagmus _ 31

Ethnicity and Absence of Optokinetic Nystagmus _ 37

Results — 37

Chapter 5 Summary, Implications, and Recommendations__ $\quad 40$

Summary — 40

Implications — 42

Recommendations _ 43

References — 44

Appendices

A. Timed Hammering Sample 46 
Table of Contents, Continued

$\begin{array}{lr}\text { B. Sample Consent Form } & 49 \\ \text { C. Approval of Institution } & 52 \\ \text { D. Neural Mechanisms of Optokinetic Nystagmus } & 54\end{array}$ 
Table Page

1 Demographic Data _ 21

2 Level of Development 23

3 Age and Development Scores _ 26

4 Relationship of Absence of Optokinetic Nystagmus and Class _ 29

5 Relationship between Absence of Optokinetic Nystagmus and Gesell Score

6 Relationship between Hand Dominance and Optokinetic Nystagmus: All Subjects _ 32

7 Relationship between Hand Dominance and Optokinetic Nystagmus: Developmental Class ___ 32

8 Relationship between Hand Dominance and Optokinetic Nystagmus : Standard Class

9 Relationship between Hand Dominance and Optokinetic Nystagmus: Low Gesell Score

10 Relationship between Hand Dominance and Optokinetic Nystagmus: High Gesell Scores

11 Relationship between Hand Dominance and Optokinetic Nystagmus: No Gesell Scores 


\section{List of Tables, Continued}

12 Relationship between Hand Dominance and Optokinetic Nystagmus: High and No Gesell Scores

13 Relationship between Ethnicity and Absence of Optokinetic Nystagmus 


\section{CHAPTER 1}

\section{INTRODUCTION}

\section{Purpose}

For the child who is classified as learning disabled, there is a scarcity of readily available evaluation procedures which yield accurate and objective information. Children with learning disabilities consistently have problems with both sensory and cognitive perceptual integration. These problems often appear early in childhood and can impair cognitive development. These deficits may also result in behavioral problems, attention deficit disorders, and hyperactivity. It is felt that early detection and intervention for potential problems could minimize or eliminate learning disabilities during academic education.

In occupational therapy practice, observation and measurement of behavior are commonly used to diagnose sensory or perceptual dysfunction. While these means of ten demonstrate the existence of some deviancy, functional relationships are difficult to clearly establish. There is a need for continuous research which will yield more information about the interactions and relationships between various systems in the brain and will aid in the development of evaluation tools which will produce both objective and reliable data (Morrison, 1985). 
The purpose of this study was to determine if a relationship exists between two variables: optokinetic nystagmus (OKN), an involuntary eye movement which is a normal physiologic function of the visual, vestibular, and cerebellar systems. Because of its vast neurological connections to the right and left side of the brain it may be an indicator of the development of hemispheric specialization. The second variable is hand dominance, which may also be an indicator of hemispheric specialization.

\section{Statement of the Problem}

Although a great deal of research in the area of learning disabilities and neurological dysfunction has been conducted, controversy continues to surround the results of these studies. Discrepancies found in results lead to confusion. Some studies indicate that a relationship exists between eye movements and learning disabilities, while other studies indicate that there is no relationship. In addition, no firm evidence exists regarding whether hand dominance is associated with certain learning disabilities, although it is believed that there is some correlation. Part of the problem lies in faulty methodology and limitations in the design of the studies, causing them to be questioned. In part, also, is the problem of concepts that are vague and difficult to define. The vestibular and visual systems are complex and are not fully delineated or understood. 
It is evident that there exists a need for continued investigation into the function and interaction between these systems. To date, there has been no research found that investigates the relationship between $\mathrm{OKN}$ and hand dominance in children.

Because this area is complex and difficult to study, it is in need of continued research so that answers may be established. Establishing the neurological basis for evaluation and treatment of learning disabilities is one such field of study. Although considerable work has been completed to establish the existence of a neurological basis for the disorder, researchers in the field cite the need for continued research to further clarify these associations.

\section{Objective and Question}

This study attempted to answer the following question:

Is there a significant relationship between optokinetic nystagmus and hand dominance in children between the ages of four and six?

The objective of this study was to determine if a significant correlation exists between hand dominance and optokinetic nystagmus. Children between the ages of four and six are expected to have a mixture of established and non-established hand dominance. If a higher percentage of children with non-established hand dominance also have abnormal optokinetic nystagmus, in comparison with those who have established hand dominance, then this study will further the knowledge 
of the interaction between the vestibular and visual systems, and hemispheric specialization.

\section{Definitions}

The following is a list of terms which were used in this research and their definitions.

Developmental class: Operationally defined as a group of students who were determined, by school authorities, to be developmentally delayed.

Hand dominance: A function of the cerebral cortex that determines the relative preference of one hand in the execution of various unimanual tasks, as measured by the Knickerbocker timed hammering sample.

Hemispheric specialization: "The process by which one part of the brain becomes more efficient at particular functions. Most specialized functions are lateralized; that is, one side of the brain is more proficient in the function than the other side" (Ayres, 1980, p. 184).

Learning disability: Operationally defined as performing below expectations on academic tasks while having average intelligence.

Optokinetic nystagmus (OKN): "An induced, jerky to-and-fro involuntary oscillation of the eyes. The reflex is elicited when the eyes follow a series of identical targets moving across the field of vision, either horizontally or vertically" (Larsen, 1979, p. 206). For the 
purposes of this research, $O K N$ is limited to the horizontal eye movements.

Perception: "The meaning the brain gives to sensory input. Sensations are objective; perceptions are subjective" (Ayres, 1980, p. 183).

Proprioception: Unconscious sensations from muscles and joints that enable the brain to know where each body part is in space.

Sensory integrative dysfunction: An irregularity or disorder in brain function that makes it difficult to integrate sensory input. "Sensory integrative dysfunctions are the basis for many, but not all, learning disorders" (Ayres, 1980, p. 184).

Standard class: Operationally defined as a group of students who were determined, by school authorities, to be developmentally normal.

Vestibular system: "The sensory system that responds to the position of the head in relation to gravity and accelerated or decelerated movement" (Ayres, 1980, p. 185).

Visual: "Pertaining to the sense of sight" (Ayres, 1980, p. 185). The sense by which external objects, light, and color are apprehended.

\section{Assumptions}

It was assumed that the sample of four to six year-old children used in this study was selected accurately to have evidence of established, as well as non-established hand dominance. It was also assumed that a significant relationship will be evident between those 
children who show an absence of $\mathrm{OKN}$ as well as non-established hand dominance.

\section{Limitations}

Possible limitations are the method of selection and size of the research sample. The sample may not be representative of the larger population of developmentally delayed and developmentally normal children. However, due to the lack of prior research on this particular subject, this study is considered a pilot study to determine if this is a valuable area for research. Thus, it was expected that findings from this study will be tentative and may not be generalizable.

In testing for $\mathrm{OKN}$, the reflex can be suppressed by the participant, although it is felt that children are less likely to suppress it than are adults. However, the cooperation of the participant is essential to attain accurate results.

Determination of hand dominance is largely subjective and determined by observation. In this study, several categories were used in order to render the determination of hand dominance as accurately and objectively as possible.

\section{Significance of the Study}

A great deal of research has been conducted to date on the function of various neurological systems and their effects on children with learning disabilities; however, not all of the variables have been 
studied. There is no evidence of research which attempts to address the relationship between $\mathrm{OKN}$ and hand dominance in children. It has been proposed that investigation into vestibular-ocular nystagmus and performance of perceptual tasks requiring ocular-motor responses would be a productive area of research (Morrison, 1985). The researcher examined this topic in this study.

Because controversy surrounds the results of work in this field, researchers call for further studies which would add to the body of knowledge that currently exists. Of primary importance in this area is the need for the "development of objectives and reliable measures whose repeated use over time generates data contributing to predictive and construct validity" (Morrison, 1985, p. 157). OKN may be shown to be useful as an accurate ard reliable evaluative tool.

Since evaluations of $\mathrm{OKN}$ and hand dominance do not require high level skills such as reading and writing, these measures can be used to evaluate children before they enter primary school. Early discovery and prevention of learning disabilities has been the goal of many researchers in this field. Often problems are discovered only after the child has failed consistently in school. By the time the child enters treatment, serious emotional and psychological problems are encountered in addition to the learning disability itself. With early diagnosis and intervention, these secondary problems might be reduced or eliminated, rendering treatment more effective and sparing the child the long term consequences of these secondary problems. 
Finally, occupational therapists have played a major role in the development of a theory base used for the evaluation and treatment of children with learning disabilities. Information added to the existing body of knowledge might further clarify and influence the role of occupational therapy in this evaluation and treatment process. 


\section{CHAPTER 2}

\section{REVIEW OF THE LITERATURE}

A review of the literature revealed that, to date, no studies exist which correlate the variables of optokinetic nystagmus (OKN) and hand dominance in children, although a considerable amount of research has been devoted to studying each variable separately and in relation to other variables.

\section{Vestibular System}

In 1958, de Quiros began studying the vestibular system and its effect on learning and has greatly influenced the thinking in this field. He found that the vestibular system has a close anatomical and functional relationship with proprioception which furnishes information about the body's position in space. This interaction of information is a fundamental requirement for later learning (de Quiros, 1976).

Ayres, an occupational therapist, has further advanced the theory base. Her findings suggest that:

while academic and other learning certainly involves portions of the cerebral cortex, those portions are not only interdependent but dependent upon lower neural structures for normal functioning. For that reason, 
remedial intervention programs must first be concerned with brain function, especially the older and lower parts. These functions are carried out through brain mechanisms (Ayres, 1972, p. 23).

Ayres (1972) also believed that the brain possesses the characteristic of plasticity that, in children, can contribute to reorganization through alternative neuronal pathways and compensation for brain damage or dysfunction. She asserted that sensory integrative therapy can effect a physiological change in the brain at this neurological level. Morrison (1985) points out that under these assumptions, a therapist is not just altering behavior through treatment, but is causing physiological changes in the brain. He states that this assumption can only be vaguely conceptualized and defined because while the measurement is of behavior, it is neurological function that is changed, making the theory difficult to support, and this stands as a major limitation.

Another drawback is that it has been difficult to separate clinical observation of dysfunction and treatment from the theory itself. Indeed, the theorists take the position of "consistently relating assessment to therapeutic intervention" (Morrison, 1985, p. 34). Thus, the delineation between problem and intervention is less clear. It is felt, however, that research in this area has moved beyond the stage of initial confirmation and that there now exists the need for research 
into areas such as the relationship between learning disorders and dysfunction in perceptual processing (Morrison, 1985).

OKN has been studied extensively in medical research and for examination, although it has not been applied to children with learning disorders. The function of the vestibular system is to stabilize the visual field. When moving objects produce visual instability, it redirects the eyes to center, the position of rest. If this compensatory vestibular reaction does not function correctly, visual-perceptual functions are disrupted, resulting in learning disorders due to suppressed visual perception (Morrison, 1985).

Pavlidis (1981) has studied the relationship of eye movements to dyslexia (a hemispheric disorder) and suggests that dyslexia is caused by ocular-motor system dysfunction. He also points to an association between erratic eye movement patterns and non-reading sequencing abilities, the functions of which stem from the left hemisphere of the brain. Thus, language and sequencing difficulties are often linked and may be affected by a dysfunction in the left hemisphere, which also stores language (Pavlidis, 1986).

Similarly, Larsen (1979) found that when an absent OKN response is observed as the tape moves from the subject's right to left, it reflects a disturbance in the pathways leading to the left hemisphere and vice versa when the stimulus moves from left to right. The absence of OKN When the tape moves from left to right indicates a disturbance in the right hemisphere which is associated with poor motor sequencing. Loss 
of OKN from right to left has been associated with language disturbance. This study used an adult population which had suffered cerebral vascular accidents; however, it delineated the relationship between OKN and hemispheric specialization.

Several researchers reported that $\mathrm{OKN}$ is useful clinically (Dix, 1980; Larsen, 1979; Morrison, 1985), not only because testing for it is non-invasive and takes little time to assess, but because it can produce objective and reliable data. Because ocular-motor responses are related to the vestibular system, researchers call for studies utilizing additional measures of that system in order to clarify other variables that contribute to the learning disability (Morrison, 1985).

Ayres (1972) hypothesized that vestibular, auditory, and somatosensory stimulus dysfunction interferes with language development and that adequate communication between the two hemispheres is especially important to reading.

Drawing from Ayres, Knickerbocker has stated that dysfunction in the vestibular system interferes with "the natural development of cerebral dominance, and secondarily to this, hand dominance" (Knickerbocker, 1980, p. 59). 


\section{Hand Dominance}

Research seems to support the concept that undifferentiated hand dominance has long been associated with learning disabilities (Ayres, 1972; Knickerbocker, 1980; Morrison, 1985; Van Camp and Bixby, 1977). Kaufman, Zalma, and Kaufman (1978) found that the establishment of hand dominance in preschool and primary grade children was significantly related to cognitive, motor, and directional variables. They suggest that the nature of the relationship was also a function of the age of the child. Nevertheless, it remains that a relationship exists, and these researchers note a need for further studies which incorporate hand dominance into the current body of knowledge about lateral cerebral specialization and interhemispheric integration. Hand dominance is usually established between the ages of four and six, and stabilized by age seven (Ayres, 1972). Therefore, it would be expected to see a mixture of established and non-established preferences in children four to six years of age.

Roszkowski and Snelbecker (1981) have reported that selfassessed hand preference is a more reliable indicator of dominance than is actual testing; however, they also found that preference indicated in hammering was the activity that most strongly correlated with hand dominance, followed by drawing and writing.

Knickerbocker (1980) has developed two means of observing the presence or absence of established hand dominance: the timed 
hammering sample, and the timed crayoning sample. These are scales of measurement that are used to assess hand dominance. While the tests are timed, the findings are subjective and considered samples of behavior.

\section{Summary}

This review of the literature revealed that while a great deal has been studied in the field of learning disabilities, there remains a need for further investigation into the relationship between the visual and vestibular systems. Hand dominance and hemispheric specialization are themes commonly found in the literature; however, the relationship between the visual and vestibular responses and hand dominance has not been established. 


\section{CHAPTER 3}

\section{DESIGN AND METHODOLOGY}

\section{Objective and Question}

The objective of this study was to determine if there was a significant relationship between the variables of optokinetic nystagmus and hand dominance. The following research question was posed: Is there a significant relationship between optokinetic nystagmus and hand dominance in children between the ages of four and six?

Subjects

A total of 120 children between the ages of four and six who attended McCollam Elementary School, 3311 Lucian Avenue, San Jose, CA, were asked to participate in this study and were given consent forms to be signed by their parents. Of this total population, 68 children returned their forms and were tested for both hand dominance and OKN.

\section{Collection Techniques}

Data were gathered by testing the children for hand dominance by using the timed hammering test described by Knickerbocker (1980), 
(see Appendix A for test description). Hammering was timed up to 20 seconds for each hand.

Children were tested for OKN using the optokinetic tape: a vinyl tape which is 15 -inches long and one-inch wide. The tape is painted with alternating black and white vertical stripes which are each one inch apart. The tape was presented to the child at eye level and moved horizontally first from left to right, then from right to left. The child was told to count the stripes as they moved past, in order to prevent the child from staring through the tape and suppressing OKN. Both the use of the OKN tape and hammering sample take less than ten minutes to administer.

\section{Procedures}

Testing was videotaped, with the participants' prior knowledge and consent, in order to assure that responses were accurately measured.

Each child's age, sex, and race were recorded. The timed hammering sample was administered first, with several factors noted to assist the researcher in determining actual hand dominance. These factors are as follows: number of hammer strikes counted for each hand, hand used first, amount of overflow observed, and performance quality which was assigned numeric values; with 1 representing weak hand grip, wild and uncontrolled strikes, and handle flipping; 2 representing moderately weak grip and occasional lack of control; and 3 
representing direct and accurate strikes which are on target. Each child was then assigned a category for hand dominance from one of three categories of hand dominance: right hand do ininant, left hand dominant, and undetermined.

OKN was recorded to reflect the absence or presence of the reflez in either or both directions.

\section{Serendipity}

After testing was completed, it was discovered that each child who was attending McCollam Elementary School at the kindergarten level had been tested for school readiness with the Gesell School Readiness Test, prior to entering school. This screening test assists with determination of each child's developmental level and is based on a series of six tests and three subtests. These tests measure performance according to expected behavior patterns in areas of motor, adaptive, language, and personal-social skills. The Gesell School Readiness Test is generally well regarded and widely used (Clark, Allen, Coley, and Schanzenbacher, 1985).

McCollam Elementary School uses the Gesell School Readiness Test to assist with determination of developmental skills and placement of each child in standard or developmental kindergarten classes. Placement is not determined solely on the basis of these scores, but by other factors as well, including a child's age, behavior and/or performance in class. 
Gesell School Readiness scores were available for 43 of the 68 children used in this study, or approximately two thirds of the sample group. It was felt that incorporating these results into this study might further assist with the corroboration and validation of results. 


\section{CHAPTER 4}

\section{DATA AND RESULTS}

The research question to be answered in this study was: Is there a significant relationship between optokinetic nystagmus and hand dominance in children between the ages of four to six.

Incorporation of Gesell School Readiness Data

When testing for optokinetic nystagmus and hand dominance was completed the reseacher discovered that the Gesell School Readiness Test had been administered to children who had entered McCollum Elementary School at the kindergarten level prior to the beginning of the school year. This test was used as a screening device to assist with determination of the level of each child's developmental skills and placement into either standard or developmental kindergarten classes.

The Gesell School Readiness test is a screening test which assesses expected behavior patterns in motor, adaptive language, and personalsocial skills. Gesell School Readiness scores were available for 43 of the 68 children who were subjects in this study. The Gesell scores and placement into standard or developmental classrooms were incorporated into this study to investigate whether they too correlated with hand dominance and/or optokinetic nystagmus. In addition these measures further served to strenghten the correlations between hand dominance 
and optokinetic nystagmus. The results will be discussed further in this chapter.

\section{Statistical Technique}

The Chi-Square $(\chi 2)$ test is the standard statistical technique chosen for this study to measure correlations among discrete variables, such as OKN and hand dominance. The $\chi 2$ test determines the significance of the differences between obtained results and results expected by chance. The value of $p$ is the probabilty that the $\chi 2$ result occurred by chance and a significant relationship is found when the probability $(p)$ is less than $(<) .05$.

\section{Demographic Data}

Demographic data are reported in Table 1. The subjects were 68 kindergarten students. Of the 68 subjects, 37 were male and 31 were female. The children ranged from 4 years 0 months to 6 years 5 months with a mean age of 5 years 4 months. 
Table 1

Demograohic Data

\begin{tabular}{|c|c|}
\hline \multicolumn{2}{|l|}{ Gender } \\
\hline Female & 31 \\
\hline Male & 37 \\
\hline \multicolumn{2}{|l|}{ Age } \\
\hline Range & 4 years 0 months to 6 years 5 months \\
\hline Mean & 5 years 4 months \\
\hline Median & 5 years 3 months \\
\hline Mode & 5 years 3 months \\
\hline \multicolumn{2}{|l|}{ Ethnicity } \\
\hline Hispanic & 25 \\
\hline Caucasian & 25 \\
\hline Black & 4 \\
\hline Asian & 14 \\
\hline \multicolumn{2}{|l|}{ Hand Dominance } \\
\hline Differentiated & 49 \\
\hline Undifferentiated & 19 \\
\hline \multicolumn{2}{|c|}{ Optokinetic Nystagmus } \\
\hline Absent & 14 \\
\hline Present & 54 \\
\hline
\end{tabular}


Regarding ethnicity, 25 children were Hispanic, 25 children were Caucasian, 4 children were Black, and 14 children were Asian. In the tests of hand dominance, 49 children showed hand dominance ( 45 right handed and 4 left handed) and 19 children showed no hand dominance. Regarding optokinetic nystagmus, 14 children demonstrated absent OKN while 54 children had present OKN.

Level of Development

Level of development was measured in two ways which shall be discussed below. The data discussed appears in Table 2.

\section{Standard or Develonmental Class}

Children were found in either classrooms for the developmentally normal or the developmentally delayed. The classes for the developmentally normal shall be referred to as "standard." The classes for children with developmental delay shall be referred to as "developmental." Of these children, 22 had been assigned to the developmental class and 46 had been assigned to the standard class. 
Table 2

Level of Develonment

\begin{tabular}{lccc}
\hline & & Class & \\
\cline { 2 - 4 } & Developmental & Standard & Total \\
\hline Low Gesell & 20 & 3 & 23 \\
High Gesell & 2 & 17 & 19 \\
No Gesell & 0 & 26 & 26 \\
\hline Total & 22 & 46 & 68 \\
\hline
\end{tabular}




\section{Gesell Score for School Readiness}

In addition, Gesell developmental scores were available for some, but not all, children. The Gesell Developmental Test (Clark, Allen, Coley, \& Schanzenbacher, 1985) is a combination of tests that result in a developmental "age" that can be compared to chronological age to determine developmental maturity and thus gauge "school readiness." Gesell scores were available for 42 children, and not available for 26 other children. Children shall be referred to as "low" or "high" Gesell scorers, or, when necessary, "children with no Gesell score." Of the 42 children for whom Gesell scores were available, 23 were low Gesell scorers and 19 were high Gesell scorers. Gesell scores were available for each of the 22 children assigned to the developmental class. Of the 22 children in the developmental class, 20 were low Gesell scorers, with only two children in the developmental class being high Gesell scorers. Therefore, for the developmental class, Gesell score and assignment into developmental class were essentially redundant measures. However, scores were missing for many children in the standard class. Of the 46 children in the standard class, 20 children had Gesell scores, and 17 of those were high Gesell scorers, and 3 children were low Gesell scorers. Gesell scores were not available for the other 22 children; therefore the status of their school readiness was not known. As will be seen, these children were older as a group than either low or high Gesell scorers. It is possible that their chronological, rather than their developmental 
age resulted in their assignment to the standard class. This is discussed below.

Age and Development Scores.

There was a strong relationship between class and age. Children in the developmental class were much younger than children in the standard class. The mean age for children in the developmental class was 4 years 11 months. The mean age for children in the standard class was 5 years 4 months $(\mathfrak{f}(66)=3.45, \mathbb{D}<.001)$. There is also a relationship between age and Gesell score, with high Gesell scorers being significantly older than low Gesell scorers. The mean age of high Gesell scorers is 5 years 4 months, the mean age for low Gesell scorers is 5 years 0 months $(1(40)=2.77,2<.01)$ which suggested that the older children displayed more maturity on the developmental measures. Interestingly, children with no Gesell scores are significantly older than either low or high Gesell scorers. Mean age for children with no Gesell score is 5 years 7 months. An ANOVA conducted on all three means was highly significant $(E(2,65)=15.61$, $\mathrm{Q}<.0001)$ (See Table 3 ). The group for which we have no developmental score is quite old for a kindergarten class. Indeed, the 17 oldest children in the entire subject 
Table 3

Age and Develooment Scores

$\begin{array}{ll}\begin{array}{l}\text { Class } \\ \text { Developmental }\end{array} & 4 \text { years } 11 \text { months } \\ \text { Standard } & 5 \text { years } 4 \text { months } \\ \text { Gesell Score } & \\ \text { Low } & 5 \text { years } 0 \text { months } \\ \text { High } & 5 \text { years } 4 \text { months } \\ \text { None } & 5 \text { years } 7 \text { months }\end{array}$

$E(2,65)=15.61, \mathbb{D}<.0001$ 
pool of 68 children were found in this group. Five of these children were older than 6 in the fall of their kindergarten year. This could indicate that assignment to the standard class occurs for one of two different reasons. Assignment could be based on observation of classroom performance, or simply because of advanced chronological age.

Because of a pattern of significant differences found between children in the standard class with high Gesell scores and no Gesell scores this age difference could be suggestive. This will be discussed in the summary of the results.

Age, Optokinetic Nystagmus and Development

There are some inferences that there may be a relationship between absence of OKN and development; that is, children who are developmentally delayed may show absence of OKN more frequently than children who are not developmentally delayed. This evidence is suggestive rather than conclusive, as it is due in part to the pattern of findings revealed by children without Gesell scores, whose developmental scores are not known. The relationship of the different measures of development to absence of OKN will be discussed in turn. 


\section{Age. Optokinetic Nystagmus and Class.}

There is a tendency for more children in the developmental class to lack OKN than for children in the standard class to lack OKN. Seven of $22(32 \%)$ children in the developmental class lack OKN, while 7 of 46 (15\%) of children in the standard class lack OKN, Chi-square $(\chi 2)$ $(1, \mathrm{~N}=68)=2.50, \mathrm{D}=.11($ See Table 4$)$.

Age, Optokinetic Nystagmus and Gesell Score

When only the 42 children with Gesell scores are considered, the relationship between development and absence of OKN is very strong. Seven of the 23 children with low Gesell scores (30\%) lacked OKN, while none of the 19 children with high Gesell scores $(0 \%$ ) lacked OKN (this $\chi 2$ is incorporated into Table 5). Children without Gesell scores are as likely to lack OKN as children with low Gesell scores (all three groups are compared in Table 5: $\chi 2(2, \mathrm{~N}=68)=6.93, \mathrm{p}<.05)$. As noted above, there is a highly significant age trend; low Gesell scorers are the youngest group, children without Gesell scores are the oldest group, and high Gesell scorers are in between these groups. The youngest children, those placed in the developmental class, and the oldest children, those without Gesell scores, are much more likely than high Gesell scorers to lack OKN, (see Table 5). Because the rated developmental age of the oldest group of children is not known, it is 


\section{Table 4}

Relationshir of Absence of Optokinetic Nystagmus and Class

\begin{tabular}{lccc}
\hline OKN & \multicolumn{2}{c}{ Class } \\
\cline { 2 - 4 } & Developmental & Standard & Total \\
\hline Absence & 7 & 7 & 14 \\
Presence & 15 & 39 & 54 \\
\hline Total & 22 & 46 & 68 \\
\hline$\chi^{2}(1, N=68)=2.50, \mathcal{D}=.11$ & &
\end{tabular}


Table 5

Relationship between Absence of Optokinetic Ny stagmus and Gesell Score

\begin{tabular}{lcccc}
\hline OKN & \multicolumn{4}{c}{ Gesell Score } \\
\cline { 2 - 5 } & Low & High & None & Total \\
\hline A.bsence & 7 & 0 & 7 & 14 \\
Presence & 16 & 19 & 19 & 54 \\
\hline Total & 23 & 19 & 26 & 68 \\
\hline
\end{tabular}

When all subjects are considered then:

$\chi^{2}(2, \mathbb{N}=68)=6.93, \mathrm{D}<.05$.

When only subjects with Gesell scores are considered then:

$\chi^{2}(1, \mathbb{N}=42)=6.93, \mathrm{D}<.03$ 
possible that the absence of OKN is associated with another measure of immaturity.

The Relationship of Hand Dominance to Absence of Optokinetic Nystagmus

Overall there was a slight tendency for children without established hand dominance to have absent OKN. Only $16 \%$ ( 8 out of 49) of the children with established hand dominance lacked OKN, while $31 \%$ ( 6 out of 19) of the children without established hand dominance lacked $\operatorname{OKN}(\chi 2(1, N=68)=1.95, p=.16)($ See Table 6).

The trend is caused by the strong relationship that exists within children of the developmental class; there is no relationship of handedness and OKN within children in the standard class (See Tables 7 and 8 ). Among children in the developmental class, 3 of the 17 children who had already established hand dominance (18\%) lacked OKN, while 4 of the 5 children without established hand dominance $(80 \%)$ lacked OKN $(\chi 2(1, N=22)=6.92, \mathbb{D}<.01)$. This is a significant finding which indicates that the children with developmental delays are more likely to be neurologically immature and that $\mathrm{OKN}$ is a good indicator of this phenomenon. Among children in the standard class, 5 of 32 with established hand dominance ( $16 \%$ ) lacked OKN, and 2 of 14 children without established hand dominance (14\%) lacked OKN ( $\chi 2$ NS). 
Table 6

Relationshio between Hand Dominance and Optokinetic Nystagmus: All Subjects

\begin{tabular}{lccc}
\hline \multirow{2}{*}{ OKN } & \multicolumn{3}{c}{ Hand Dominance } \\
\cline { 2 - 4 } & Differentiated & Undifferentiated & Total \\
\hline Absence & 8 & 6 & 14 \\
Presence & 41 & 13 & 54 \\
\hline Total & 49 & 19 & 68 \\
\hline
\end{tabular}

$\chi^{2}(1, N=68)=1.95, \mathcal{D}=.16$

Table 7

Relationship between Hand Dominance and Optokinetic Nystagmus: Develoomentalclass

\begin{tabular}{lccc}
\hline \multirow{2}{*}{ OKN } & \multicolumn{4}{c}{ Hand Dominance } \\
\cline { 2 - 4 } & Differentiated & Undifferentiated & Total \\
\hline Absence & 3 & 4 & 7 \\
Presence & 14 & 1 & 22 \\
\hline Total & 17 & 5 & \\
\hline$\chi^{2}(1, \mathrm{~N}=22)=6.92, \mathrm{D}<.01$ & &
\end{tabular}


Table 8

Relationshio between Hand Dominance and Optokinetic Nystagmus: Standard Class

\begin{tabular}{lccc}
\hline \multirow{2}{*}{ OKN } & \multicolumn{3}{c}{ Hand Dominance } \\
\cline { 2 - 4 } & Differentiated & Undifferentiated & Total \\
\hline Absence & 5 & 2 & 7 \\
Presence & 27 & 12 & 39 \\
\hline Total & 32 & 14 & 46 \\
\hline$\chi^{2}$ NS. & & & \\
\hline
\end{tabular}


The pattern of relationships of $\mathrm{OKN}$ and hand dominance is similar when the measure of development used is Gesell score (see Tables 9,10 and 11). The relationship of hand dominance and absent OKN is also seen among children with low Gesell scores, as would be expected. Because no high Gesell scorers had absent OKN it is impossible to assess the relation of hand dominance and absence of $\mathrm{OKN}$ in high Gesell scorers. Children with no Gesell scores, who looked similar to low Gesell scorers in the earlier analysis, show no relationship. Because hand dominance is generally established by age six, the fact that this group is significantly older, as noted previously, could explain the lack of relationship in this group. Among low Gesell scorers 3 of 18 children with already established hand dominance (17\%) lacked OKN. Four of 5 children without established hand dominance $(80 \%)$ lacked OKN. The reader is reminded that for low Gesell scorers class assignment and Gesell score are essentially redundant measures: the children without established hand dominance are the same children in both of the analyses discussed above $(\chi 2(1, \mathbb{N}=23)=7.41, \mathbb{D}<.01)$. As noted previously, this finding is a significant one and shows that subjects with absent $\mathrm{OKN}$ are more likely to have undifferentiated hand dominance. Among the high Gesell scorers a chi square test cannot be computed because no high Gesell scorers lacked OKN. Similarly, among children with no Gesell scores 5 of 18 children with established hand dominance (28\%) lacked OKN and 2 of 8 children without established 
Table 9

Relationship between Hand Dominance and Ootokinetic Nystagmus: Low Gesell Scores

\begin{tabular}{|c|c|c|c|}
\hline \multirow[t]{2}{*}{ OKN } & \multicolumn{3}{|c|}{ Hand Dominance } \\
\hline & Differentiated & Undifferentiated & Total \\
\hline Absence & 3 & 4 & 7 \\
\hline Presence & 15 & 1 & 16 \\
\hline Total & 18 & 5 & 23 \\
\hline \multicolumn{4}{|c|}{$\chi^{2}(1, N=23)=7.41,2<.01$} \\
\hline \multicolumn{4}{|c|}{$\begin{array}{c}\text { Table } 10 \\
\frac{\text { Relationshio between Hand Dominance and Optokinetic Nystagmus: }}{\text { High Gesell Scores }}\end{array}$} \\
\hline \multirow[t]{2}{*}{ OKN } & \multicolumn{3}{|c|}{ Hand Dominance } \\
\hline & Differentiated & Undifferentiated & Total \\
\hline Absence & 0 & 0 & 0 \\
\hline Presence & 13 & 6 & 19 \\
\hline Total & 13 & 6 & 19 \\
\hline
\end{tabular}

$\chi^{2}$ cannot be computed 
Table 11

Relationshie between Hand Deminance and Optokinetic Nystagmus:

No Gesell Scores

\begin{tabular}{lccc}
\hline \multirow{2}{*}{ OKN } & \multicolumn{3}{c}{ Hand Dominance } \\
\cline { 2 - 4 } & Differentiated & Undifferentiated & Total \\
\hline Absence & 5 & 2 & 7 \\
Presence & 13 & 6 & 19 \\
\hline Total & 18 & 8 & 26 \\
\hline$\chi^{2}$ NS & & &
\end{tabular}


hand dominance (25\%) lacked $\mathrm{OKN}$ ( $\chi 2$ NS). As a final check, a $\chi 2$ test was computed combining high Gesell scorers with children without Gesell scores. No relationship was found between lack of OKN and handedness for this group, (see Table 12). In this group 5 of 31 children with established hand dominance (16\%) lacked OKN and 2 of 14 children without established hand dominance (14\%) lacked OKN ( $\chi 2 \mathrm{NS}$ ).

Ethnicity and Absence of Optokinetic Nystagmus

Interestingly, a strong relationship was found between ethnic group and absence of OKN (See Table 13). Hispanic children were much less likely to lack OKN than Caucasian, Black or Asian children. Only 1 of 25 Hispanic children (4\%) lacked OKN, while 9 of 25 Caucasians (36\%). 1 of 4 Blacks (25\%) and 3 of 14 Asians (21\%) lacked OKN $(\chi 2(3, N=68)=7.89, \mathrm{D}<.05)$. Ethnic group did not affect any of the other measures of interest (age, hand dominance, or developmental level). Further study is indicated for this possible ethnic difference.

Results

Overall this study found a slight tendency for children without established hand dominance to have absent OKN. Among children in the developmental class there was evidence of a significant relationship between $\mathrm{OKN}$ and hand dominance, while the standard class children showed no significant relationship at all. In addition, a significant 
Table 12

Relationship between Hand Dominance and Optokinetic Nystagmus: High and No Gesell Scores

\begin{tabular}{lccc}
\hline \multirow{2}{*}{ OKN } & \multicolumn{3}{c}{ Hand Dominance } \\
\cline { 2 - 4 } & Differentiated & Undifferentiated & Total \\
\hline Absence & 5 & 2 & 7 \\
Presence & 26 & 12 & 38 \\
\hline Total & 31 & 14 & 45 \\
\hline$\chi^{2}$ NS & & &
\end{tabular}

Table 13

Relationship between Ethnicity and Absence of Optokinetic Nystagmus

\begin{tabular}{lccccc}
\hline \multirow{2}{*}{ OKN } & \multicolumn{5}{c}{ Ethnic Group } \\
\cline { 2 - 6 } & Hispanic & Caucasian & Black & Asian & Total \\
\hline Absence & 1 & 9 & 1 & 3 & 14 \\
Presence & 24 & 16 & 3 & 11 & 54 \\
\hline Total & 25 & 25 & 4 & 14 & 68 \\
\hline
\end{tabular}

$\chi^{2}(3, \mathrm{~N}=68)=7.89, \mathrm{D}<.05$ 
relationship was found between $\mathrm{OKN}$ and place ment into a developmental class. 


\section{CHAPTER 5}

\section{SUMMARY, IMPLICATIONS AND RECOMMENDATIONS}

\section{Summary}

The purpose of this research was to investigate the relationship between hand dominance and optokinetic nystagmus in children, in order to contribute to the study of the complex interactions between the vestibular and visual systems. The question was posed: Is there a correlation between hand dominance and OKN in children four to six years of age. After an extensive literature review, it was found that no research has been reported on the relationship between hand dominance and $\mathrm{OKN}$; however, it was indicated that this was a valuable area for further research. This study did not provide evidence of a relationship between hand dominance and $\mathrm{OKN}$ in the general population; however, other findings were found to be significant and may serve as a foundation for further research into OKN.

For this study, hand dominance and OKN were measured in 68 elementary school children between the ages of four and six. These children were divided into both developmental and standard classrooms with the help of the Gesell School Readiness test.

This research found that there was a significant relationship between hand dominance and $\mathrm{OKN}$, but only for those subjects in the developmental class $\left(\chi^{2}=(1, N=22)=6.92, \mathrm{D}<.01\right)$ or for subjects with 
low Gesell scores $\left(\chi^{2}=(1, N=23)=7.41, \mathbb{D}<.01\right)$. For those subjects in the standard class, there was no significant relationship. Overall, when all subjects were considered, there was no significant relationship found between $O K N$ and hand dominance $\left(\chi^{2}=(1, N=68)=1.95, D=.16\right)$. Thus, children who exhibit absence of $\mathrm{OKN}$ and who are in a developmental class are more likely to have undifferentiated hand dominance. While this prediction may be of limited clinical value, it adds to the study of the interactions between the visual system and hemispheric specialization.

Of particular interest, are the findings of a significant relationship between absence of $\mathrm{OKN}$ and the Gesell development scores. When looking only at the 42 subjects with available Gesell scores, absence of OKN was found only in those children with low Gesell scores and not at all in children with high Gesell scores $\left(\chi^{2}(1, \mathbb{N}=42)=6.93\right.$, $\mathrm{p}<$ .03). This may be the most useful relationship found in this study. From this result it might be implied that absence of $O K N$ is an indicator of developmental delay. Underscoring this relationship is the strong tendency of children in the developmental class to lack OKN as compared to those in the standard classroom $\left(\chi^{2}(1, \mathrm{~N}=68)=2.50, \mathrm{p}=.11\right)$. This too gives rise to the question of whether a relationship exists between the absence of $\mathrm{OKN}$, the child's age, and neurological development.

The impact of age on these results is of particular interest and cannot be overlooked. The subjects in the developmental class were 
significantly younger than those in the standard class. The children with no Gesell scores were significantly older than those in the standard class. This age difference has bearing on the results, since both of these groups contained all of the subjects who lacked OKN while all children with high Gesell scores had OKN. A possible explanation would be that the older children, who had no Gesell scores, were placed in the standard classroom based on chronological rather than developmental age. Because the rated developmental age of these children is not known, this remains speculation and the fact that absence of OKN may be associated with some other measure of neurological immaturity cannot be ruled out. This is an area for which further research is strongly indicated.

Another area that warrants further investigation is that of the relationship between ethnicity and absence of OKN. It is not known why Hispanic children were much less likely to lack OKN than were children of other ethnic origins $\left(\chi^{2}(3, N=68)=7.89, \underline{2}<.05\right)$. No possible explanations for ethnic differences are offered here.

\section{Implications}

Although OKN was not significantly correlated with hand dominance in the total population, it was strongly correlated with other factors such as developmental scores and developmental age and as such, the Optokinetic Nystagmus test could be considered a valuable 
screening tool when used in conjunction with other developmental screening tests. The continued investigation into its feasibility as an evaluative screening tool is indicated. This study can serve as a model in this research.

\section{Recommendations}

This study points to 3 areas for which further research is indicated. 1) Further research is strongly indicated to investigate the relationship between age and $\mathrm{OKN}$. 2) The relationship between ethnicity and absence of OKN is also an area that warrants further study. 3) Because this was an inital study, it is recommended that further research which studies the relationship of OKN and other measures of neurological maturity be conducted. 


\section{References}

Ayres, A. J. (1972). Sensory integration and learning disorders. Los Angeles: Western Psychological Services.

Ayres, A. J. (1980). Sensery integration and the child. Los Angeles: Western Psychological Services.

Clark, P. N., Allen, A. S., Coley, I. L., \& Schanzenbacher, K. E. (1985). Instruments to evaluate childhood performance skills. In P. Clark \& A. Allen (Eds.), Occupational Therapy for Children, 192. St. Louis, MO: The C. V. Mosby Com pany.

de Quiros, J. B. (1976). Diagnosis of vestibular disorders in the learning disabled. Journal of Learning Disabilities, 2(1), 50-58.

Dix, M. R. (1980). The mechanism and clinical significance of optokinetic nystagmus. The Journal of Laryngelogy and Otology, 24, 845-864.

Kaufman, A. S., Zalma, R., \& Kaufman, N. L. (1978). The relationship of hand dominance to the motor coordination, mental ability, and right-left awareness of young normal children. Child Develonment. 49, 885-888.

Knickerbocker, B. M. (1980). A holistic aporoach to the treatment of Learning disorders. Thorofare, NJ: Charles B. Slack, Inc.

Larsen, G. L. (1979). Optokinetic nystagmus: Objectifying the prognosis for the ability to learn. Journal of Neurosurgical Nursing, 11(4), 205-207. 
Morrison, D. C. (1985). Neurobehavioraland perceptual dysfunctions in learning disabled children. Lewiston, NY: C. J. Hogrefe, Inc.

Pavlidis, G. (1981). Sequencing, eye movements and the early objective diagnosis of dyslezia. In G. Pavlidis \& T. Miles (Eds.), Dyslexia Research and its Aoplication te Education. New York: John Wiley \& Sons.

Pavlidis, G. (1986). Eye movements: The diagnostic key to dyslexia? Contemeerary Optemetry, 5(2), 7-12.

Roszkowski, J. J., \& Snelbecker, G. E. (1981). Children's, adolescents', and adults' reports of hand preference: Homogeneity and discriminating power of selected tasks. Journal of Clinical Neuropsychelogy, 3(3), 199-213.

Van Camp, S. S., \& Bixby, M. B. (1977). Eye and hand dominance in kindergarten and first-grade children. Merrill-Palmer Quarterly, 23(3), 129-139.

Van Hof-Van Duin, J., \& Mohn, G. (1983). Optokinetic and spontaneous nystagmus in children with neurological disorders. Behavioral Brain Research, 10, 163-175. 
APPENDIX A

TIMED HAMMERING SAMPLE 


\section{PLEASE NOTE:}

Copyrighted materials in this document have not been filmed at the request of the author. They are available for consultation, however. in the author's university library.

These consist of pages:

47-48 
APPENDIX B

SAMPLE CONSENT FORM 


\section{Consent Form}

Your child is invited to participate in a study examining the relationship between certain eye movements and hand dominance. We hope to determine if the simple tests we plan to use might be useful in detecting potential learning disabilities. Your child was selected to participate because we are testing children between the ages of four and six.

If you allow your child to participate, an occupational therapist will test eye movements using a tape printed with alternating black and white stripes. This tape is held at eye level and moved horizontally from left to right and then from right to left. Your child will be instructed to look. straight ahead and count the stripes as they move past.

Hand dominance will be tested by having your child sit at a table and hammer within a marked circular space.

These tests will take no longer than ten minutes to administer. Testing will take place at McCollam School, with the permission of the school principal and your child's teacher. Because we wish to be able to accurately measure and interpret the findings, we will be videotaping the test procedure.

Any information that is obtained in connection with this study and that can be identified with your child will remain confidential and will only be disclosed with your permission or as required by law. If you give us your permission by signing this document we plan to disclose the overall test results to San Jose State University Graduate Committee and Department of Occupational Therapy in a thesis report summarizing the outcome of the findings.

Your decision whether or not your child will participate will not prejudice your future with McCollam Elementary School, or with the Department of Occupational Therapy at San Jose State University. If you decide to participate, you are free to withdraw your consent and to discontinue participation at any time without prejudice.

If you have any questions, we expect you to ask us. If you have any additional questions later, Anita Thompson, (415) 843-2141, or Guy McCormack, Department of Occupational Therapy, (408) 277-2981, will be happy to answer them.

You will be given a copy of this form to keep. 
YOU ARE MAKING A DECISION WHETHER OR NOT YOUR CHILD WILL PARTICIPATE. YOUR SIGNATURE INDICATES THAT YOU HAVE DECIDED TO LET YOUR CHILD PARTICIPATE, HAVING READ THE INFORMATION PROVIDED ABOVE.

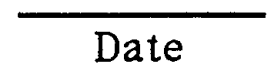

Signature of parent or guardian

Signature of Investigator 
APPENDIX C

APPROVAL OF INSTITUTION 


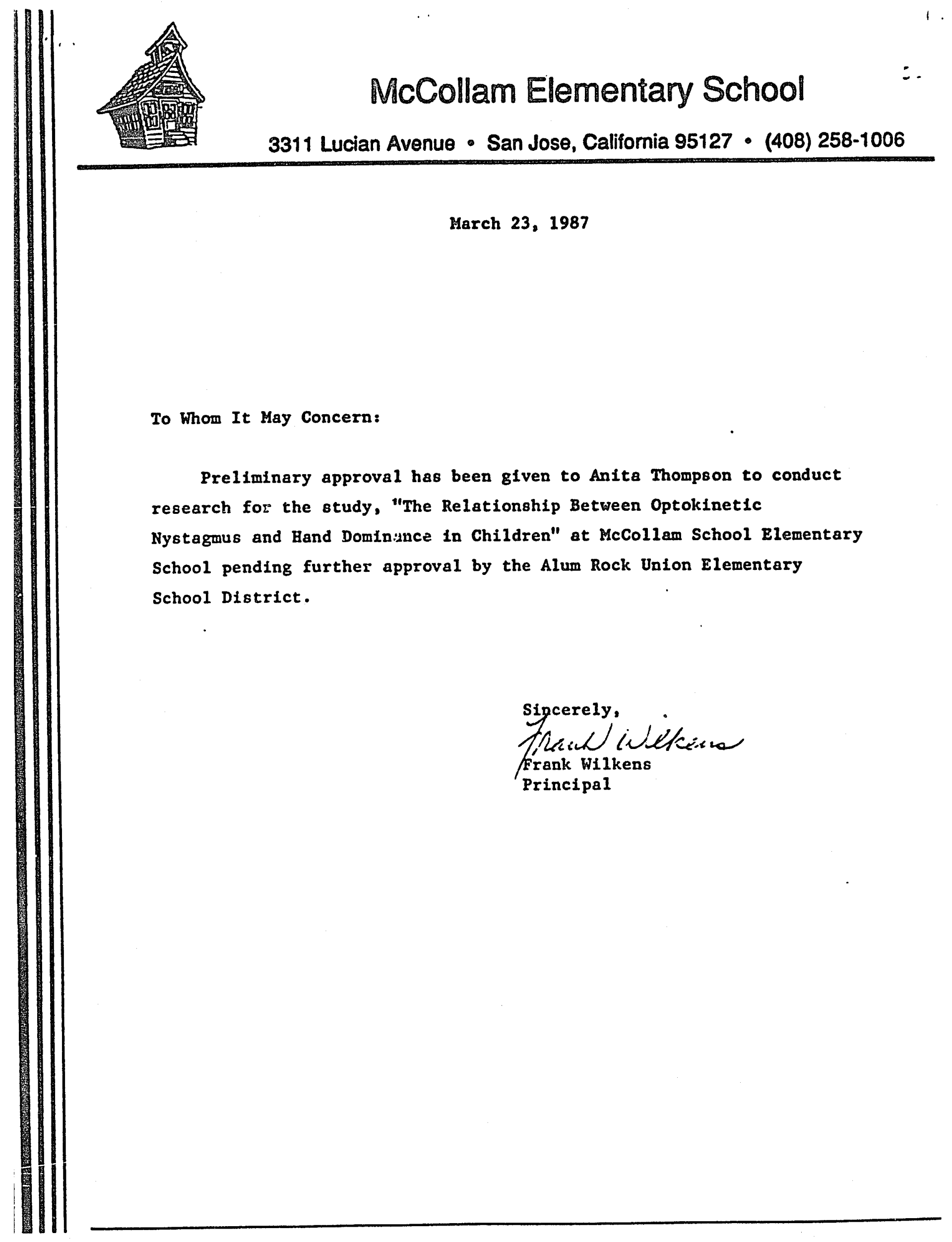


APPENDIX D

NEURAL MECH ANISMS OF OPTOKINETIC NYST AGMUS 


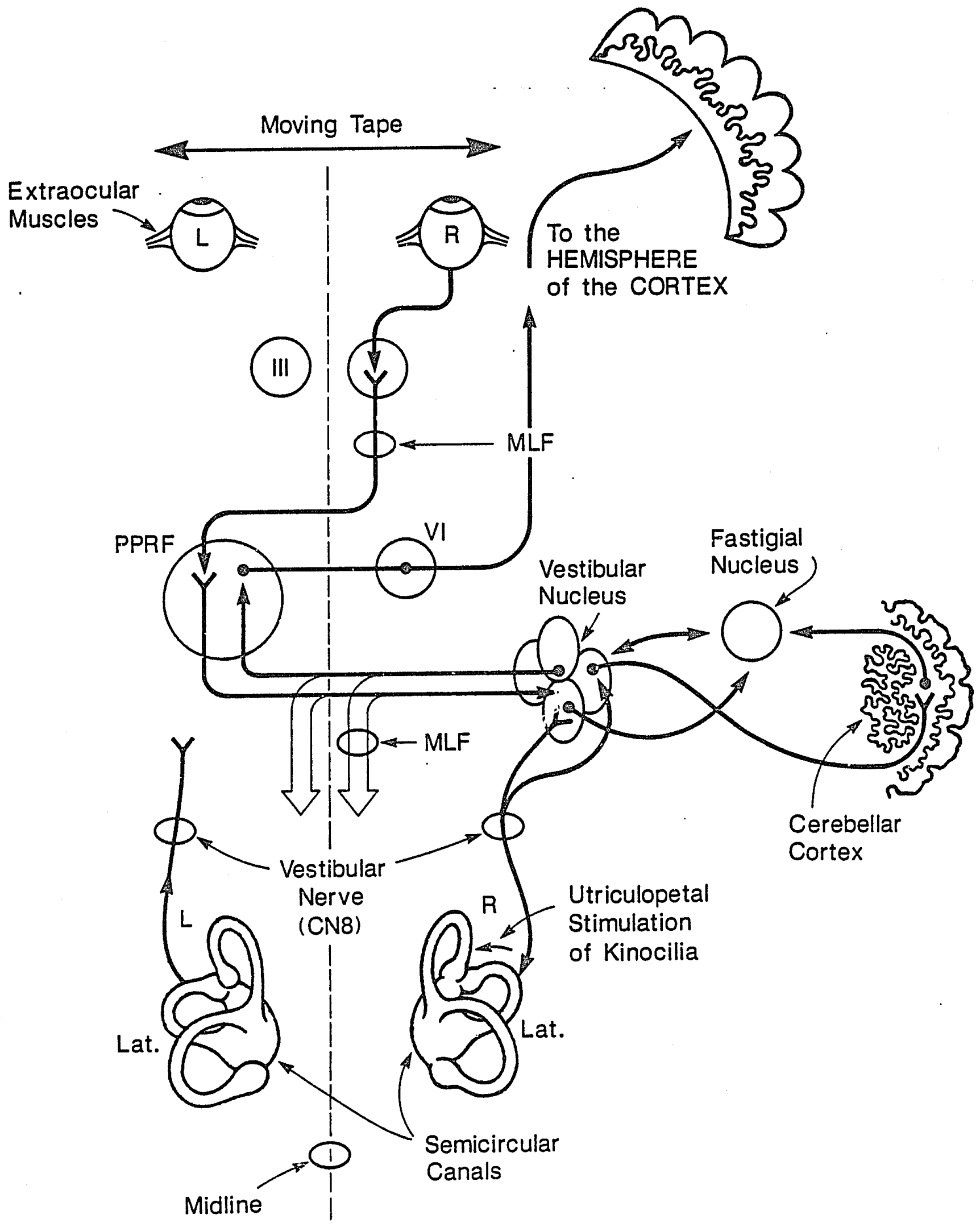

